\title{
EB virus-specific IgA in serum of patients with infectious mononucleosis and of healthy people of different ages
}

\author{
JOAN M. B. EDWARDS AND MARION WOODROOF \\ From the Virus Reference Laboratory, Central Public Health Laboratory, Colindale Avenue, \\ London NW9 5HT, UK
}

SUMmaRY The following sera were tested for EB virus-specific IgA: serial sera from 61 cases of infectious mononucleosis (IM) and from $195 \mathrm{EBV} \mathrm{IgG} \mathrm{positive} \mathrm{healthy} \mathrm{students;} \mathrm{single} \mathrm{sera} \mathrm{from}$ each of 1469 persons of different ages, 63 cases of untreated Hodgkin's disease, and 22 neonates.

EBV specific IgA was found in the sera from $88 \%$ of cases of IM, from $18.5 \%$ of EBV IgG positive healthy students, and in $13.5 \%$ of repeat samples from the same students three years later. The incidence of EBV IgA varied from 5 to $30 \%$ at different ages in single sera from EBV IgG positive persons aged 2 to 70 years. The higher percentages occurred in the age groups where recent seroconversion rates were high. Fifteen percent of sera from cases of Hodgkin's disease were positive for EBV IgA, an incidence similar to that for healthy adults in the age group 25-45 years. None of the EBV IgG positive sera from neonates gave a positive reaction for EBV IGA.

On primary infection with EB virus, serum IgG specific for the viral capsid antigen (EBVCA) is produced within a few days. The initial rise occurs usually before any laboratory investigation has been made, and after this the antibody titre varies little and persists for life. We have shown that EB virus specific IgM can be demonstrated in every patient with infectious mononucleosis (IM), that it develops early, and that it disappears within a few months; two-thirds of our sera were negative at three months and all at one year (Blake et al., 1976). Detailed studies of IgA in IM or in a healthy population have not been reported, but Ho et al. (1976) did not find IgA in any of their control subjects, and Henle and Henle (1976) found that less than $5 \%$ of the controls were positive in their surveys of IgA.

Both these groups of workers found high titres of EBV IgA in serum from over $90 \%$ of cases of nasopharyngeal carcinoma. Ho et al. (1978) have suggested that the finding of a high serum EBV IgA titre might be an indicator for persons liable to develop nasopharyngeal carcinoma. They reported IgA in the serum of $28 \%$ of patients with Burkitt's lymphoma. No studies of serum IgA have been reported in Hodgkin's disease. This disease, however, is of some interest because Rosdahl et al. (1974)

Received for publication 4 April 1979 and Muñoz et al. (1978) reported a slightly higher incidence of Hodgkin's disease in subjects whose sera had been positive for heterophil antibody (HA) within the last 10 years than in HA-negative controls.

For these reasons we have studied: the rise and fall of EBVCA IgA in serial samples from university students developing IM; the presence of EBV IgA in serial samples from healthy students; and the incidence of IgA in single sera from subjects of all ages and from untreated cases of Hodgkin's disease. Our aim was to determine: at what stage EBV IgA appeared after infection; its rate of disappearance, if at all, from the serum; and the expected incidence of sera positive for $\operatorname{IgA}$ in the population.

\section{Material and methods}

The following sera were examined:

1 serial sera, including pre-illness and post-convalescent sera, from 61 cases of IM from the university study partially reported in 1971 (University Health Physicians and Public Health Laboratory Service Laboratories, 1971);

2 serial sera from healthy students known to have IgG antibody for EB virus; 140 at university and 55 at a boarding school for boys (Hoskins et al., 1976);

31469 single sera sent to the Cross-Infection Refer- 
ence Laboratory at Colindale for anti-streptolysin O (ASO) antibody estimation, representing patients of all ages;

463 sera from untreated cases of Hodgkin's disease, kindly supplied by Professor Peckham and Dr. B. Jameson from the Royal Marsden Hospital;

522 sera from babies less than 6 weeks old who were found to have maternal EBV IgG.

TESTS

1 Sera of all IM cases were screened for IgG, IgA, IgM, and $\mathrm{HA}$; IgG was also titrated.

2 All ASO sera from children under 10 years were screened for IgG, IgA, and IgM. Any positive for IgM were also tested for HA.

3 For reasons of economy, the remaining ASO sera and the sera from healthy students were screened for IgG and, if positive, for IgA. IgM and HA tests were performed only on those sera positive for IgA in order to identify unrecognised acute IM.

4 All sera positive for either IgM or IgA were tested for rheumatoid factor. When enough serum was available IgM tests were repeated on the macroglobulin fraction from a sucrose density gradient.

5 Thirty-eight sera found strongly positive for IgA were titrated out.

\section{METHODOLOGY}

The indirect immunofluorescence tests for EBVCA IgG have been described by Sumaya et al. (1975). For IgG and IgA, an acetone-fixed preparation from a suspension of an EB3 cell line was incubated with a dilution of 1 in 8 of the unknown serum for 1 hour at $37^{\circ} \mathrm{C}$ and, after washing, was treated with either anti-human IgG/FITC or anti-human IgA/FITC conjugate. IgM was detected as described by Edwards and McSwiggan (1974). A preparation from P3HR1 cell line (sometimes called HR-1K) was incubated with a dilution of 1 in 8 of the unknown serum for 3 hours and, after washing, treated with anti-human IgM/FITC conjugate.

The conjugates for IgG and IgM tests were obtained from Wellcome Research Laboratory and the IgA test from Dako-immunoglobulins. The classspecificity of the anti-human IgA conjugate was confirmed by performing parallel titrations on six sera strongly positive for EBV IgA. The conjugate was used unabsorbed and after absorption with a sample of purified IgA supplied by Dr. Drew of the Department of Experimental Pathology, Birmingham. Negative results were obtained in the tests using the absorbed conjugate. A further check on the specificity of the anti-IgA conjugate was the examination of EBV IgG positive sera from 22 infants under 6 weeks of age. The EBV IgG present in these sera was presumed to be of maternal origin because IgM was absent. It is known that IgA does not pass the placental barrier so the infant sera should be devoid of $\operatorname{IgA}$. The IgG titres ranged from 1 in 16 to 1 in 512. None of these sera reacted in the IgA test. The absence of $\operatorname{IgA}$ staining, even by the four sera with titres of 1 in 512, indicates that the anti-human IgA conjugate is not reacting with IgG subclasses 1, 2, and 4 (Mawhinney et al., 1973).

The presence of HA was detected in the IM sera by the full Lee Davidsohn technique by Dr. McSwiggan at the Central Middlesex Hospital, London (University Health Physicians and Public Health Laboratory Service Laboratories, 1971). The other sera were tested by the Monospot slide test in our laboratory (Ortho Diagnostics Inc). This test uses horse erythrocytes and a short prior absorption with guinea-pig kidney emulsion or ox cell stroma.

Rheumatoid factor was detected at a dilution of 1 in 8 with the latex Rheuma-Wellco Test (Wellcome Research Laboratories).

\section{Results}

Figure 1 compares the proportions of the serial sera from 61 cases of IM occurring in the university population which were positive for each class of EBV-specific immunoglobulin and for HA before and at different times after the onset of illness. Sera were positive for IgG in the majority at onset and always thereafter. All sera were positive for IgM and HA in the onset sample and/or the convalescent sample. The HA test remained positive in more patients and for a longer period than the IgM; it was still present in two-thirds of cases at four months and in one case at 13 months after onset. $\operatorname{IgA}$, on the other hand, was detected in only $88 \%$ of the acute and/or the convalescent serum. After three months only $20 \%$ were still positive, but IgA was still detectable 18 to 30 months later in $10 \%$.

Sera from 140 healthy female university students were selected because the students had had EBV IgG in their serum at the time of entry to the university and no recent history of IM. It was supposed that although a few might have had a recent silent infection the majority would have been infected some months or years previously. The sera taken at entry and at graduation three or four years later were tested for $\operatorname{IgA}$. In no case was $\operatorname{IgA}$ found in the later specimen and not in the former; $26(18 \%)$ were positive at entry, and $19(13.5 \%)$ were still positive at graduation.

Similarly, of 55 boys who had serum EBV IgG on entry to boarding school at 11 to 13 years, five also had IgA. Four of these five were positive two years later, and, of the three we were able to test at three and four years, all were still positive. 

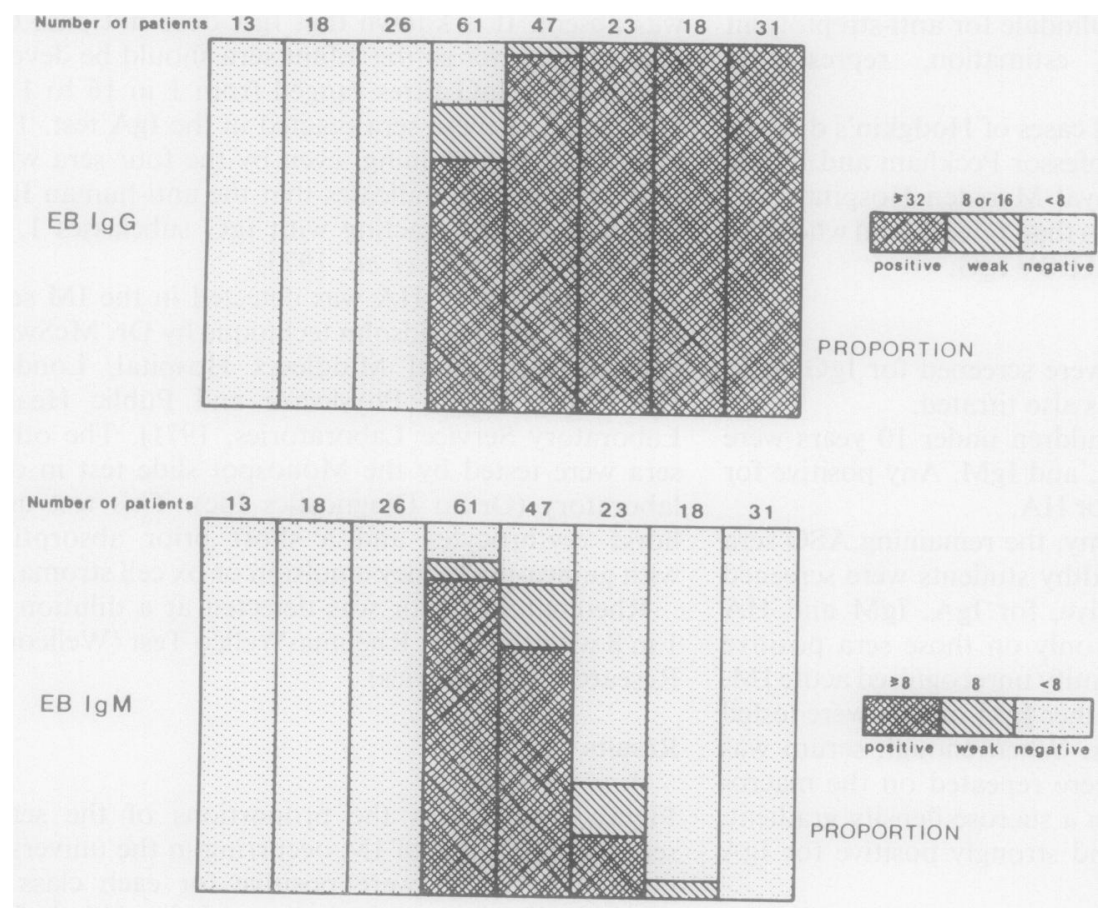

Fig. 1 Illustrates seroconversion and persistence of $E B$ virus

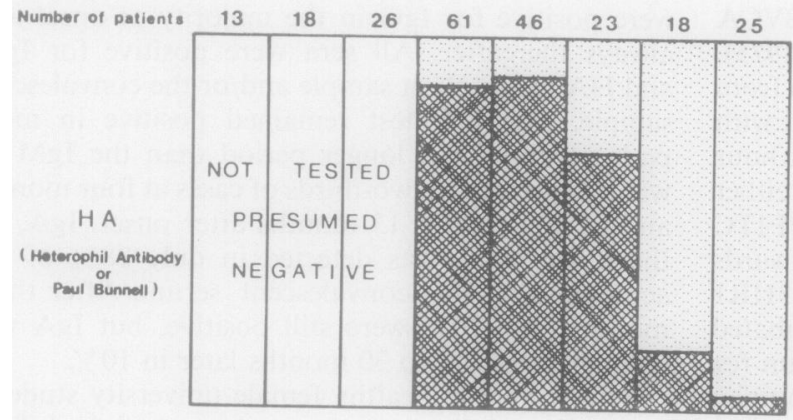
specific $\operatorname{IgG}, \operatorname{IgM}$, and IgA and heterophil antibody in 61 cases of infectious mononucleosis.

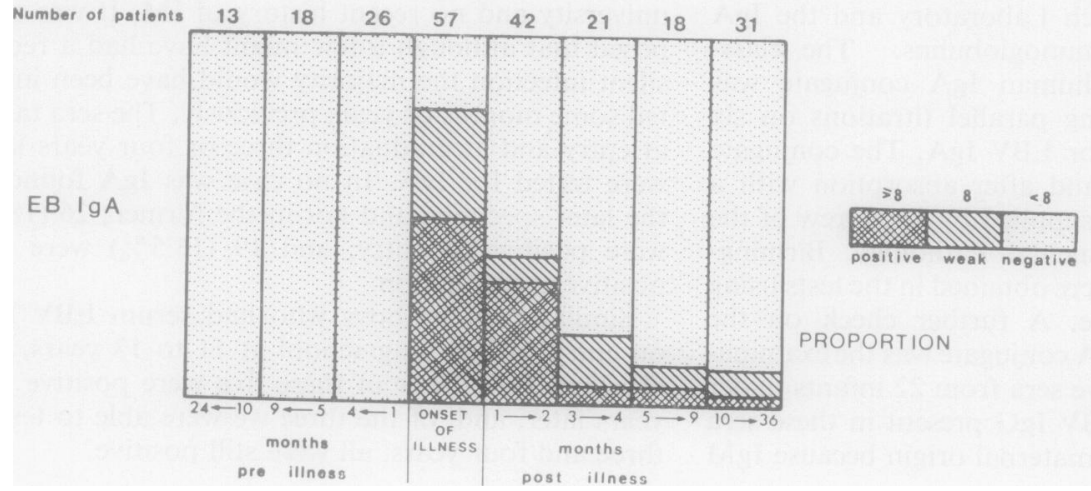




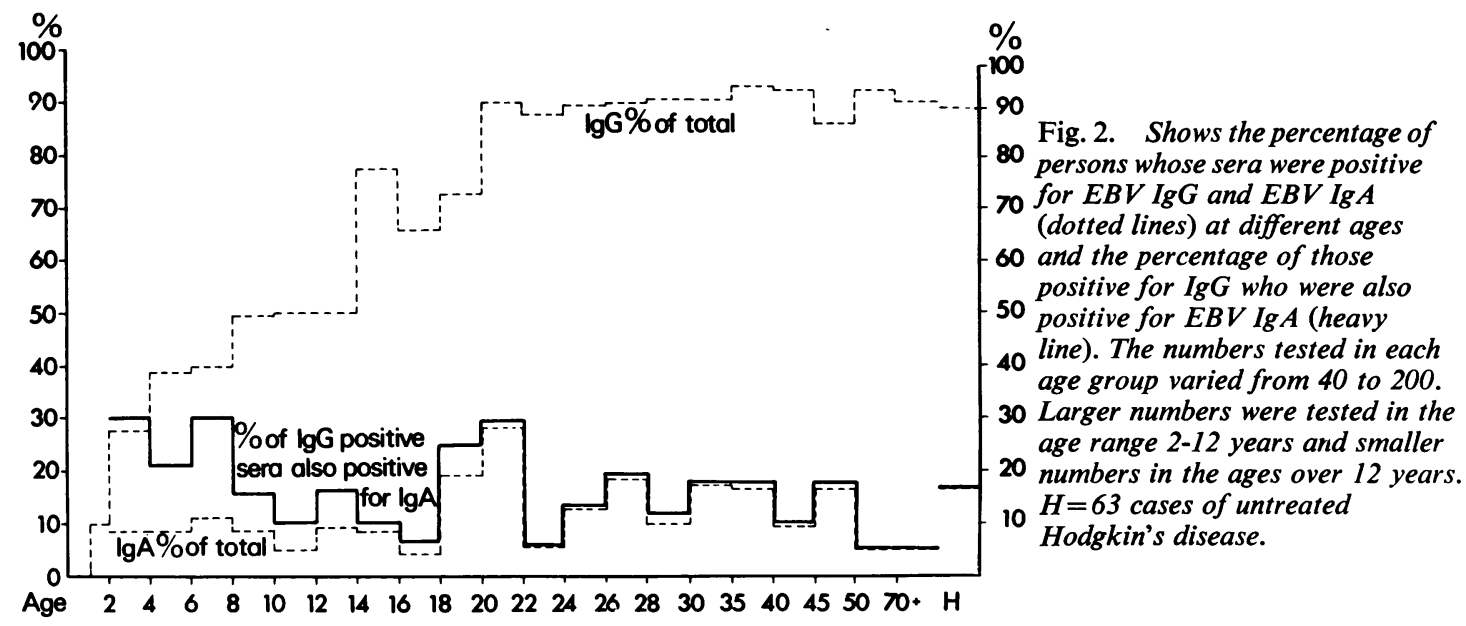

In Fig. 2 the upper and lower lines show the percentage of ASO sera positive for EBV IgG and EBV IgA, respectively, plotted against age. The third, heavy line shows the percentage of the IgG positive sera that are positive for IgA.

The incidence of EB virus infection in relation to age, as shown by the IgG curve, is similar to that found by Pereira et al. (1969). There is a higher incidence of infection at two periods, from 1 to 6 years and from 14 to 20 years, resulting in steep rises in the curve from 0 to $40 \%$ and from 51 to $90 \%$ at these ages. The percentage of sera positive for IgA of the total number at each age is affected in the lower age groups by the small number of EBVinfected persons. The heavy line shows the sera positive for $\operatorname{IgA}$ as a percentage of the number positive for IgG. This varies from 5 to $30 \%$, and there are two peaks coincident with or slightly after the steep rises in the IgG line.

The percentage of the Hodgkin sera positive for IgG was the same as that for the adult population $(90 \%)$, and the percentage of IgG positive Hodgkin sera also positive for IgA was also similar at $16 \%$.

The EBV IgM test was positive on the whole serum in 16 of the ASO sera so the test was repeated on the macroglobulin fraction obtained after centrifugation on a sucrose density gradient. Eight sera were confirmed as IgM positive and presumed to be from cases of acute EB virus infection masquerading as streptococcal infection. Six of these sera were both HA- and IgA-positive. The two HA-negative sera were from children under 3 , and it is known that the HA test can be negative in young children (Joncas et al., 1974). Unfortunately, there was insufficient serum to be tested for IgA. The other eight sera were negative after fractionation. Seven of these were positive for rheumatoid factor, which was the prob- able cause of the false result in the test on whole serum.

\section{TITRATION RESULTS}

EBV IgA was usually detectable only at a 1 in 8 dilution, but 38 of the sera showing strong reactions at 1 in 8 were titrated further and only one gave a titre over 1 in 64. In contrast, a case of nasopharyngeal carcinoma gave a serum titre of 1 in 512 .

\section{Discussion}

There is therefore some suggestion from these results that $\operatorname{IgA}$ is produced during the acute illness in quantities nearly always detectable by our methods but that in $80-90 \%$ of patients it decreases to a level that we cannot detect within a few months, similar in its time scale with the disappearance of IgM. In contrast with IgM, however, $10-20 \%$ of patients maintain a detectable amount of $\operatorname{IgA}$ for many years, possibly for a lifetime. It would be interesting if these $10-20 \%$ are long-term excretors of virus, such as those described by Miller et al. (1973).

The titres of IgA detected in our sera are not as great as the majority of those measured in cases of nasopharyngeal carcinoma and their relatives by Henle and Henle (1976) and Ho et al. (1978). It is interesting to note that the concentration of $\operatorname{IgA}$ in positive sera in our population lies within such narrow limits. As nasopharyngeal carcinoma associated with EB virus has not been described in the United Kingdom their suggestion that the presence of IgA may be an indication of susceptibility to this disease is not relevant here.

Our thanks are due to the University Health Physicians and Public Health Laboratories for allowing us 
to test the sera from the EB virus antibody survey, to the Cross Infection Reference Laboratory for provision of the ASO sera and records; to Mrs Adams, of the Photographic Department, for preparation of the charts; and to Dr M. S. Pereira and Mrs Joy for advice and help in the preparation of this report.

\section{References}

Blake, J. M., Edwards, J. M. B., Fletcher, W., McSwiggan, D. A., and Pereira, M. S. (1976). Measurement of heterophil antibody and antibodies to EB viral capsid antigen IgG and IgM in suspected cases of infectious mononucleosis. Journal of Clinical Pathology, 29, 841-847.

Edwards, J. M. B., and McSwiggan, D. A. (1974). Studies on the diagnostic value of an immunofluorescence test for EB virus-specific IgM. Journal of Clinical Pathology, 27, 647-651.

Henle, G., and Henle, W. (1976). Epstein-Barr virusspecific IgA serum antibodies as an outstanding feature of nasopharyngeal carcinoma. International Journal of Cancer, 17, 1-7.

Ho, H. C., Kwan, H. C., Ng, M. H., and Chau, J. C. (1976). Epstein-Barr virus-specific IgA and IgG serum antibodies in nasopharyngeal carcinoma. British Journal of Cancer, 34, 655-660.

Ho, H. C., Kwan, H. C., Ng, M. H., and de-Thé, G. (1978). Serum IgA antibodies to Epstein-Barr virus capsid antigen preceding symptoms of nasopharyngeal carcinoma (Letter). Lancet, 1, 436.

Hoskins, T. W., Fletcher, W. B., Blake, J. M., Pereira, M. S., and Edwards, J. M. B. (1976). Epstein-Barr virus antibody and infectious mononucleosis in a boarding school for boys. Journal of Clinical Pathology, 29, $42-45$.
Joncas, J., Boucher, J., Granger-Julien, M, and Filion, C. (1974). Epstein-Barr virus infection in the neonatal period and in childhood. Canadian Medical Association Journal, 110, 33-37.

Mawhinney, H., Haire, M., and Adair, B. M. (1973). The use of cord serum and indirect viral immunofluorescence as a method of evaluating the immunological specificity of fluorescein-labelled anti-human IgA conjugate. Journal of Immunological Methods, 2, 309-313.

Miller, G., Niederman, J. C., and Andrews, L. (1973). Prolonged oropharyngeal excretion of Epstein-Barr virus after infectious mononucleosis. New England Journal of Medicine, 288, 229-232.

Muñoz, N., Davidson, R. J. L., Witthoff, B., Ericsson, J. E., and de-Thé, G. (1978). Infectious mononucleosis and Hodgkin's disease. International Journal of Cancer, 22, 10-13.

Pereira, M. S., Blake, J. M., and Macrae, A. D. (1969). Epstein-Barr virus antibody at different ages. British Medical Journal, 4, 526-527.

Rosdahl, N., Olesen-Larson, S., and Clemmensen, J. (1974). Hodgkin's disease in patient with previous infectious mononucleosis: 30 years experience. British Medical Journal, 2, 253-256.

Sumaya, C. V., Henle, W., Henle, G., Smith, M. H. D., and LeBlanc, D. (1975). Seroepidemiologic study of Epstein-Barr virus infections in a rural community. Journal of Infectious Diseases, 131, 403-408.

University Health Physicians and Public Health Laboratory Service Laboratories (1971). Infectious mononucleosis and its relationship to Epstein-Barr virus antibody. British Medical Journal, 4, 643-646.

Requests for reprints to: Dr Joan M. B. Edwards, Virus Reference Laboratory, Central Public Health Laboratory, Colindale Avenue, London NW9 5HT, UK. 